Chapter 10

\title{
AGRICULTURE AND UNDERNUTRITION
}

\author{
Derek Headey and William A. Masters
}

For most of modern history, agricultural development has focused on reducing poverty and food insecurity, typically by attempting to provide sufficient dietary energy for survival and work (see Chapters 1 and 9). For these basic needs, rapid population growth in the late 20th century, especially, required much greater productivity of staple cereals such as rice, wheat, and maize, as well as potatoes, cassava, and other root crops, to meet human energy requirements, especially in the lowest-income regions where people remain at the margin of subsistence. These few "starchy" staples have evolved and been selected to produce the most dietary energy per unit of cost in terms of labor, land, water, and other inputs.

Once a person's energy needs are met, health and longevity depend on other aspects of human nutrition, which is a complex biological process. Human foods contain several dozen essential nutrients needed for health that cannot be synthesized within the body. "Macronutrients" include essential amino acids (protein) and fatty acids (fats) that serve as building blocks for cellular activity and can also be burned for dietary energy, in contrast to vitamin and mineral "micronutrients" that are essential for health but do not directly provide energy for physical activity. A wide range of dietary components other than essential nutrients also contribute to health, notably fiber and water as well as phytochemicals (produced by plants), and the form of a nutrient may be important for bioavailability, such as the vitamin B-12 and heme iron in some animal-sourced foods. Each nutrient or other component often serves multiple biological functions affecting physical growth, cognitive development, immune system strengthening, and prevention of specific diseases. Many nutrients can also be harmful at high doses, sometimes in ratio terms relative to other dietary components. Foods may contain harmful toxins or antinutrients that block absorption, and nutrient utilization is heavily influenced by infection and other aspects of a person's health.

Improving nutrition goes far beyond the quantity of food. Moreover, while poverty and food security are often monitored on the basis of consumption 
per person, nutritional needs vary greatly by age, and undernutrition tends to be most costly and most pronounced among children less than two years of age (Victora et al. 2009). Undernutrition also has intergenerational dimensions, with poor maternal nutrition-especially during pregnancy-resulting in children who are malnourished even before birth.

The inherent complexity of human nutrition, combined with the logistical and ethical difficulty of conducting research on how diets affect health, makes it extremely challenging to predict the impacts of agricultural policies, structures, systems, and practices on nutrition outcomes such as height, weight, anemia, and other markers. Agricultural change can influence what people eat through income and price effects, but also influence nutrition through the disease environment via crops (for example, molds that spawn mycotoxins), livestock (for example, zoonotic diseases, fecal contamination of the environment), and exposure to hazardous chemicals (for example, pesticides). Moreover, even the dietary impacts of agricultural interventions are likely to be complex, especially since the main burden of undernutrition occurs among infants and very young children (for example, 6-24 months of age) rather than the broader family.

Obtaining rigorous empirical evidence on agriculture-nutrition linkages is made more challenging by institutional separation and methodological differences between agricultural and nutritional sciences. Nutrition research is a very new field, with most sources of data and analytical methods having been developed in the late 20th century. Agricultural research is much older, with large subfields such as plant genetics that were founded in the late 19th century. Economics spans both topics, studying farm household behavior, markets, and food choice since the late 18th century, but its techniques are typically not available to either agricultural or nutrition researchers and rarely include much biological detail about crops, livestock, or people. Hence it is little surprise that the scientific literature on agriculture-nutrition linkages has, for most of recent history, remained extremely limited (see von Braun [1995] for an early exception).

After 2005, sharp increases in world food prices, combined with gradually increasing concerns and new discoveries about diet-related diseases around the world, led to a burst of research about how agricultural projects could improve health. These studies were largely confined to evaluations of geographically focused interventions designed to help target households diversify their own production and nutritional knowledge to increase the household's own dietary diversity, diet quality, and nutritional status (Leroy and Frongillo 2007; Girard et al. 2012; Masset et al. 2012; Ruel and 
Alderman 2013; Haselow, Stormer, and Pries 2016; Ruel, Quisumbing, and Balagamwala 2018). Reviews of that literature focus on how each household's nutritional outcomes relate to their own farm production, in contrast to systems-level research that tries to understand the nutritional impacts of larger-scale agricultural growth and transformation processes (PinstrupAndersen 2013). The economic development and agricultural economics literature generally focuses on these larger-scale processes, including the impacts of investments that drive the creation and adoption of new technologies, the development of new value chains, the evolution of retail outlets (including supermarkets), and changes in both domestic and international trade, but typically does not measure nutrition outcomes in particular (PinstrupAndersen 2013). This chapter aims to bridge these two literatures on agriculture and nutrition, including studies of geographically focused projects and programs, as well as the nutritional impacts of agricultural growth and transformation processes.

In light of these knowledge gaps, the objectives of this chapter are to

1. conceptualize the variety of linkages between agriculture and nutrition;

2. describe methodological challenges to evaluating these agriculturenutrition linkages;

3. summarize existing evidence on these linkages, focusing on lessons from the program evaluation literature, microeconomic research (largely based on household surveys), and meso- or macroeconomic research on markets, agricultural growth, and transformation; and

4. identify important research and policy implications from the existing evidence.

At the outset we define the parameters of our review as follows.

First, we typically use the term agriculture to mean the farm production of crop and livestock commodities; agribusiness to mean commercial suppliers of farm inputs and wholesale purchasers of farm commodities; food markets to mean storage, shipment, and transformation of food into final products including packaged foods and meals away from home; and policy as a shorthand for any public sector or philanthropic intervention or program that aims to alter these activities. These are all interrelated influences on what we will call livelihoods, meaning all of a household's activities, including both agriculture and nonfarm work. Putting these pieces together, the chapter will focus on agricultural and food systems, meaning the aggregate outcome of 
interactions between these components at the scale of an entire village, region, country, or the world as a whole.

Second, this chapter focuses on undernutrition-defined as insufficient intake of nutrients and healthy foods relative to biological needs, and the resulting deficiencies such as anemia and failure to achieve a child's genetic potential such as linear growth-rather than problems linked to excessive intake of total energy, salt, and harmful foods that lead to obesity and dietrelated diseases such as hypertension and diabetes. The two types of malnutrition are connected, as many people who suffer from dietary insufficiencies in some dimensions also have excesses in others (for example, stunting in childhood followed by obesity in later life, or ongoing micronutrient deficiencies during weight gain), but excessive intake of harmful foods is less likely than dietary insufficiency to be caused by agricultural production and supply constraints. As this chapter will show, agricultural change can raise food intake where deficiencies are most widespread, while excesses that lead to obesity and diet-related disease are more closely tied to nonfarm activity, market conditions, and food demand. Excessive intake clearly links back to agriculture through demand for ingredients in unhealthy foods such as sugar and other carbohydrates, but we would hypothesize a fundamental asymmetry in agriculture-nutrition linkages: improving agricultural production can help poor people fill deficiencies, especially for children in poor rural households, but after intake has risen, attempting to use agriculture against obesity can be like pushing on a string.

Third, our review of the linkages between agriculture and undernutrition is not intended to be universally comprehensive, but focused on results of policy-relevant research about systemic interventions or processes that alter nutrition outcomes at the scale of an entire population. As noted above, there are many existing reviews of agriculture-nutrition projects designed to help individual farm families grow nutrient-dense foods via homestead gardening or livestock transfers. These interventions often have some efficacy, especially in remote areas for families with limited access to purchased food, but they are likely very expensive per household reached, are rarely implemented on a large scale, especially by governments, and may well lack sustainability given their frequent dependence on highly intensive interactions between implementers and subjects. To improve nutrition among all people in a given location, systemic change in agriculture almost always involves specialization and trade through local, regional, and global food markets. Even in poor, isolated places like Ethiopia, rural households obtain most of their nonstaple food from markets (Sibhatu and Qaim 2017), since each farm's output is inevitably 
much less diverse and unstable than the requirements of a healthy diet. The project/program literature on agriculture and nutrition also says little about agriculture's role in driving income changes, food price changes, or livelihood-related changes in health and nutrition. The project/program literature is not a sufficient basis for designing nutrition-sensitive agricultural policies. This review focuses on the broader question of how agriculture-livelihoods, farming practices, food systems, and policy interventions-influences diets and nutrition outcomes.

\section{A Conceptual Framework for Linking Agriculture to Nutrition}

Several previous studies have sought to conceptualize the complex relationship between agriculture and nutrition (Hoddinott 2011; Headey, Chiu, and Kadiyada 2012; Kadiyala et al. 2014). Here we focus on three basic linkages that encompass a number of specific interconnections, as illustrated in Table 10.1.

The first basic linkage is the role of agriculture in influencing household income. In low-income countries there are far more workers than there are nonfarm employment opportunities, and those at greatest risk of undernutrition are the poorest people who have no choice but to do at least some farming to meet daily energy needs. Their total incomes determine affordability and utilization of a wide range of nutritionally relevant goods and services, including food, health care, and education as well as water, sanitation, and hygiene (WASH). Economywide analyses of productivity growth in different agricultural and nonagricultural sectors estimate the direct and indirect benefits to different socioeconomic groups (see Diao, Hazell, and Thurlow 2010 and Chapter 9 for a review). These studies tend to find that investments in staple cereals often have the largest benefits for poor groups. Productivity growth in cereals has direct benefits to adopting farm households, many of whom are very poor. But productivity growth in cereals clearly also affects the level and stability of local food prices if cereals are not perfectly tradable, which has real income implications for rural and urban populations. Increases in farmer income and production also raise demand for nonagricultural goods and services, including labor, leading to higher wages and higher incomes for nonadopting households, particularly in the rural nonfarm economy. Hence, investments in staple cereals tend to have highly progressive impacts on the income distribution, although their benefits to catalyzing broader economic growth are still much debated (Dercon and Gollin 2014). 
TABLE 10.1 Conceptualizing basic and specific linkages between agriculture and nutrition

\begin{tabular}{|c|c|c|}
\hline Basic linkage & Specific linkage & Comments \\
\hline \multirow{2}{*}{$\begin{array}{l}\text { 1. Agriculture as a source } \\
\text { of income (growth, equality, } \\
\text { poverty) }\end{array}$} & 1a. Farm profits & $\begin{array}{l}\text { - Majority of the poor still work in } \\
\text { agriculture }\end{array}$ \\
\hline & $\begin{array}{l}\text { 1b. Off-farm income (off-farm } \\
\text { and nonfarm wage incomes and } \\
\text { profits) }\end{array}$ & $\begin{array}{l}\text { - Substantial numbers of poor } \\
\text { people work in off-farm or nonfarm } \\
\text { occupations }\end{array}$ \\
\hline \multirow[t]{3}{*}{$\begin{array}{l}\text { 2. Agriculture as a source of } \\
\text { (relative) food prices }\end{array}$} & $\begin{array}{l}\text { 2a. Changes in production affect } \\
\text { relative prices of different foods }\end{array}$ & $\begin{array}{l}\text { - Many foods are imperfectly trad- } \\
\text { able, implying prices are heavily } \\
\text { influenced by local supply and } \\
\text { demand }\end{array}$ \\
\hline & $\begin{array}{l}\text { 2b. Changes in trade policies } \\
\text { affect relative prices of different } \\
\text { foods }\end{array}$ & $\begin{array}{l}\text { - Many food sectors are still highly } \\
\text { protected }\end{array}$ \\
\hline & $\begin{array}{l}\text { 2c. Changes in transport and } \\
\text { storage affect relative prices of } \\
\text { different foods }\end{array}$ & $\begin{array}{l}\text { - Many foods are highly perishable } \\
\text { and not traded long distances }\end{array}$ \\
\hline \multirow[t]{4}{*}{ 3. Agriculture as a livelihood } & $\begin{array}{l}\text { 3a. Farming practices affect time } \\
\text { use of parents and children }\end{array}$ & $\begin{array}{l}\text { - Women's time use may be associ- } \\
\text { ated with less care toward young } \\
\text { children }\end{array}$ \\
\hline & $\begin{array}{l}\text { 3b. Farming practices can direct- } \\
\text { ly affect health through diseases, } \\
\text { exposure to chemicals, and level } \\
\text { of physical activity }\end{array}$ & $\begin{array}{l}\text { - Zoonotic diseases, including enter- } \\
\text { ic and pulmonary infections } \\
\text { - Exposure to pesticides, herbicides } \\
\text { - Physically arduous tasks during } \\
\text { pregnancy }\end{array}$ \\
\hline & $\begin{array}{l}\text { 3c. Agricultural livelihoods affect } \\
\text { empowerment of women and } \\
\text { children }\end{array}$ & $\begin{array}{l}\text { - Women's control of agricultural } \\
\text { assets is highly variable }\end{array}$ \\
\hline & $\begin{array}{l}\text { 3d. Agricultural livelihoods influ- } \\
\text { ence access to nutrition-relevant } \\
\text { goods and services }\end{array}$ & $\begin{array}{l}\text { - Remoteness and low population } \\
\text { density reduce access to health, } \\
\text { education, family planning, and } \\
\text { WASH services }\end{array}$ \\
\hline
\end{tabular}

Source: Authors' construction.

Note: WASH = water, sanitation, and hygiene.

A second linkage between agriculture and nutrition is through food prices. In coastal cities that trade freely with the rest of the world, easily shipped food commodities can originate anywhere, so prices are set by demand and supply among all trading partners. In the poorest rural areas, however, poor infrastructure and poor governance often limit access to distant markets, so local agriculture plays a larger role. Spatial and seasonal variation in prices tends to be greatest in the places where malnutrition is most widespread, especially for perishable products such as eggs, fresh dairy, and many fruits and vegetables. 
For these items, transport and storage cost is so high that prices, even in coastal cities, will be determined by national agricultural systems (Headey and Alderman 2019). In these situations, production is "non-separable" from consumption (Singh, Squire, and Strauss 1986; de Janvry, Fafchamps, and Sadoulet 1991), in the sense that farm output depends on local demand, so agriculture-nutrition linkages work through prices as well as income. For example, fresh milk is highly perishable and expensive to transport, so farm families with a lactating cow have much lower-cost access to milk each day and are more likely than others to feed milk to their children (Hoddinott, Headey, and Dereje 2015). More generally, the imperfect tradability of many fresh foods means that we should expect to see significant associations between local production patterns and local consumption patterns, and even between household production and household consumption (Jones 2017a; Sibhatu and Qaim 2018).

A third basic linkage involves the broader non-income dimensions of agricultural livelihoods and encompasses farming practices and their effects on time use and exposure to health hazards, cultural institutions influenced by agriculture (such as women's control over assets), and the remoteness dimension of agricultural livelihoods as it pertains to access to nutrition-relevant goods and services. These specific linkages are complex and, unlike the income and price pathways, often characterized by negative connotations: agriculture as a risk factor for poor health, for poor care practices, for diseases stemming from livestock ownership. In a dynamic sense, however, the transformation of agriculture involves adoption of modern farming practices in place of traditional practices. Sometimes modern practices may be beneficial to health and nutrition (for example, more-modernized livestock management, labor-saving technologies, improved storage facilities), and sometimes they may not be, especially if improperly used (for example, pesticide use). Examples are provided below.

\section{Measurement and Analysis of Agriculture- Nutrition Linkages}

The conceptual framework presented above points to how empirically challenging it can be to evaluate the complex linkages between agriculture and nutrition. Here we emphasize some of the main indicators regularly used to analyze agriculture-nutrition linkages, as well as some of the analytical tools that can be used. 


\section{Anthropometric Markers of Nutrition}

Many surveys collect height, weight, and age of children 0-59 months of age, for comparison with the sizes of healthy children in standardized anthropometric measures of malnutrition (WHO 2006). The most widely used metric of whether a population is achieving its genetic growth potential is height at each age, measured in standard deviation units known as z-scores. In a healthy population, the resulting height-for-age measure (HAZ) has a normal distribution around a mean of 0 , with a negative or positive score for children who happen to be short or tall for genetic or other reasons. A common threshold for extreme shortness is $\mathrm{HAZ}<-2$. By definition, in healthy populations about 2.5 percent of children would have such low $\mathrm{HAZ}$ scores, but in malnourished populations the fraction is often more than 40 percent. Not all short children have had their growth stunted by nutritional deprivation, but for practical purposes all children with $\mathrm{HAZ}<-2$ are classified as such. HAZ is thought of as the best all-encompassing marker for chronic malnutrition, reflecting as it does the cumulative impact of repeated nutritional insults. In contrast, a low weight-for-height $\mathrm{z}$-score (WHZ) - with WHZ $<-2$ defining wasting - is thought of as a marker of acute malnutrition, reflecting recent nutritional insults, such as inadequate food, or recent morbidities such as diarrhea. Many data sources such as the USAID-funded Demographic and Health Surveys (DHS) or UNICEF's Multiple Indicator Cluster Surveys (MICS) also record the height, weight, and age of adult women and sometimes adult men, and low body mass is often used as a marker of maternal undernutrition. Beyond anthropometry, the DHS also records hemoglobin levels and anemia status for women and children. Like stunting and wasting, anemia has many nonfood causes-related to infections, in particular.

Figure 10.1 illustrates how stunting, wasting, and anemia vary across the (young) life cycle of children 0-59 months of age in recent DHS rounds. The figure illustrates the critical importance of the so-called 1,000-day window of opportunity, which refers to the period from conception to a child's second birthday (Victora et al. 2009). The importance of undernutrition in utero is demonstrated by the fact that in this sample almost 20 percent of children are stunted at birth, and almost 15 percent are wasted at this age. From 0-6 months there is little systematic increase in stunting, as many children are protected from infections and inadequate nutrient intake by exclusive or at least predominant breastfeeding. However, from approximately 6-20 months, stunting rates increase precipitously from around 20 percent to 40 percent, marking this period as one of progressive growth faltering. Thereafter, 
FIGURE 10.1 Stunting, wasting, and anemia prevalence in recent DHS rounds, by child age

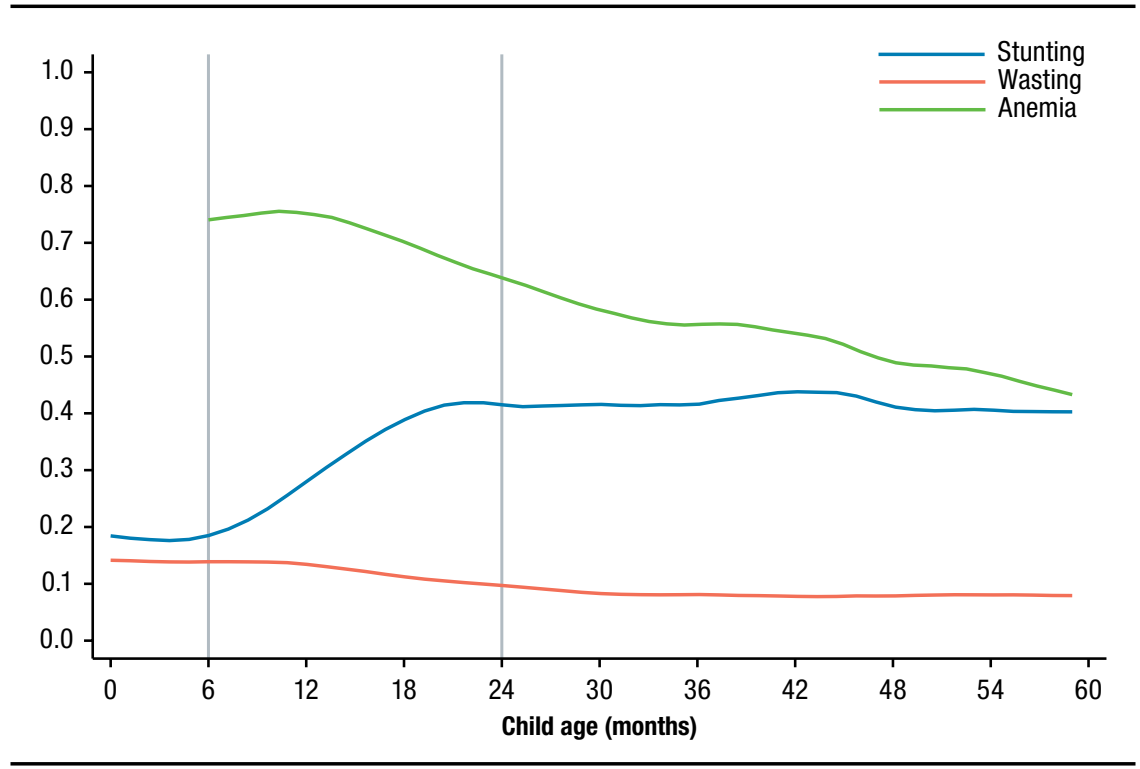

Source: Authors' estimates from DHS data from Headey, Stifel et al. (2017).

Note: DHS = Demographic and Health Surveys. Data are for 44 countries, with samples sizes of 296,370 (stunting), 284,784 (wasting), and 139,356 (anemia). Estimates are based on local polynomial smoothing using the LPOLY command in STATA 14.

stunting rates stabilize at a population level, even though individual children may experience catch-up growth after the first two years of life (or, conversely, become stunted). Wasting generally peaks at about 10-12 months of age, although wasting patterns vary substantially across countries. Anemia, which is only recorded from 6 months onward, also peaks at 10-12 months of age and gradually declines thereafter.

These dynamics of undernutrition in young children reveal important clues as to the determinants of undernutrition. First, a significant amount of growth faltering takes place in utero, suggesting maternal undernutrition is a major problem in developing countries. Second, most growth faltering, and much of the incidence of anemia and wasting, takes places in the 6-to-20month window. In this window, children have weak immune systems, are increasingly exposed to pathogens and repeated infections (diarrhea, environmental enteric disorder, pulmonary infections, anemia), and are introduced to nutritionally deficient diets and poor feeding practices.

These dynamics also have important implications for nutritional research. Wasting is likely to be more sensitive to, or better explained by, recent shocks, 
and some studies have indeed linked wasting to agroecological shocks (for example, in Nepal). Stunting or HAZ, however, substantially reflects past shocks, and this measure should be more sensitive to shocks that occurred in the first 1,000 days of life. However, as Alderman and Headey (2017) point out, regression analyses of various underlying determinants should typically exclude children less than 24 months of age, since these children have not yet been fully exposed to the various nutritional insults or protective factors that determine their growth trajectory.

\section{Survey Data on Individual and Household Diets}

Diets are a key linkage between agriculture and nutrition, but measuring diets is extremely challenging. Economists have typically focused on household diets derived from food consumption or expenditure modules, and historically focused on per capita calorie intake rather than other nutrients. Nutritionists, however, have been more interested in measuring individual diets, particularly those of mothers and young children, and more concerned with measuring dietary quality, typically proxied by dietary diversity metrics (Ruel, Harris, and Cunningham 2013).

Both approaches face several significant problems. First, it is costly and time-consuming to measure actual quantities of foods consumed, particularly at the individual level. Second, in most cases researchers want a latent measure of "usual diets," but concerns over recall errors typically limit recall to very recent periods. This approach minimizes between-person errors at the expense of within-person errors, because diets vary seasonally and because many food items are simply not consumed at high frequency (Ruel, Harris, and Cunningham 2013; Thorne-Lyman, Spiegelman, and Fawzi 2014).

As a quick, inexpensive, and easily measured indicator of dietary quality, nutritionists have proposed dietary diversity metrics, usually based on 24-hour recall of consumption of major food groups (Ruel, Harris, and Cunningham 2013). An example of child dietary diversity data from the DHS is given in Table 10.2. The first column focuses on 7 aggregated food groups, while the second column refers to 14 more-disaggregated groups that respondents listed. The use of the 7 food groups has been extensively investigated and validated, and a 4-group threshold has been proposed as an indicator of minimum dietary diversity, as it is relatively successful at predicting mean micronutrient adequacy (FANTA 2006). Researchers have also advanced maternal dietary diversity scores and household dietary diversity, though a recent review finds a lack of standardization in their use in the agriculture-nutrition literature 
TABLE 10.2 Food groups listed in phases 5 and 6 of the Demographic and Health Surveys (DHS)

\begin{tabular}{ll}
\hline $\begin{array}{l}\text { Aggregated food groups in dietary } \\
\text { diversity score (7 groups) }\end{array}$ & $\begin{array}{l}\text { Disaggregated food groups } \\
\text { (14 groups) }\end{array}$ \\
\hline (1) Starchy staples & (1) Grains \\
& (2) Roots/tubers \\
(2) Legumes/nuts & (3) Legumes/nuts \\
(3) Vitamin A-rich fruits/vegetables & (4) Vitamin A-rich fruits \\
& (5) Vitamin A-rich vegetables \\
(4) Other fruits/vegetables & (6) Other fruits \\
& (7) Dark green leafy vegetables \\
(5) Dairy & (8) Other vegetables \\
(6) Eggs & (9) Fresh/powdered cow's milk \\
(7) Flesh foods & (10) Infant formula \\
& (11) Eggs \\
& (12) Meat/organs \\
\hline
\end{tabular}

Source: Authors' construction.

(Verger et al. 2019). Nevertheless an important area for future research is to advance more cost-effective ways of measuring usual diets.

\section{Survey-Based Analyses of Agricultural Production and Agricultural Livelihoods}

Unfortunately, nutrition surveys such as the DHS and MICS have very limited information on agriculture, including only occupational status of both parents and ownership of agricultural land and livestock. As the previous section illustrated, however, agricultural production and livelihoods have many different dimensions that may influence nutrition outcomes, including time use, farming practices as they relate to livestock, use of chemical inputs and levels of physical activity, women's empowerment, and access to nutritionrelevant goods and services. Information on these types of indicators is generally only contained in household surveys, particularly those with an agricultural focus such as the World Bank's Living Standards Measurement Study-Integrated Surveys on Agriculture (LSMS-ISA). Agriculture and nutrition data are also collected together in some USAID-funded Feed the Future 
surveys conducted by IFPRI and other international and national organizations. LSMS-ISA, for example, now include modules devoted to parental time use. IFPRI also developed the Women's Empowerment in Agriculture Index (WEAI) to increase understanding of women's roles in five key domains: (1) decisions about agricultural production, (2) access to and decision-making power about productive resources, (3) control of use of income, (4) leadership in the community, and (5) time allocation (Alkire et al. 2012). Other surveys have also incorporated expanded WASH modules, including a focus on livestock-related WASH (Headey and Hirvonen 2016; Headey, Hoddinott, and Park 2017).

Despite improvements in the availability of agricultural production and livelihood data, there are still many knowledge gaps. For example, relatively little research focuses on agricultural markets, or nutrition-related agricultural extension services, particularly as they relate to diversification out of staple crops into more nutrient-rich crops and livestock products. And many agricultural/economic surveys still do not include sufficient nutritional indicators. In light of this, Pingali and Ricketts (2014) propose that agricultural household surveys incorporate a minimum set of nutrition indicators, including anthropometric and biochemical indicators for children and mothers, household and individual dietary diversity data, and market-level food supply data on availability and price.

Several papers have also tried to explore the drivers of dietary diversity in national per capita terms by utilizing food supply data from the FAO Food Balance Sheets, which report estimates of calorie, fat, and protein consumption from different foods. Choudhury and Headey (2017) use these data to construct measures of the diversification of food supplies, particularly the share of calories sourced from nonstaple foods. The Global Dietary Database project has derived alternative estimates of food intake based on Bayesian modeling of individual dietary recall survey data and has found significant discrepancies between the resulting estimates of many countries' population means and the FAO's estimates of national average consumption, particularly for vegetables (Micha et al. 2015).

\section{Food Prices and Markets}

Price data are an underutilized resource for understanding the affordability of nutritious foods. All countries collect food price data through consumer price surveys (usually through national bureaus of statistics), but these data are rarely publicly available. The FAO also collates producer price data as well as market level data, but chiefly only for staple foods, and agricultural ministries 
also often collect agricultural market surveys. Globally, the International Comparison Program (ICP) of the World Bank also collects prices of standardized food products approximately every five years, as discussed by Headey and Alderman (2019). And at the most granular level, household survey data also collect price data from households and often from community survey modules. Our perception is that these data are underused, however.

Price data can be nutritionally informative in a number of different ways. Consumer price indices weight the prices of different foods according to prevailing consumption patterns, whereas Masters et al. (2018) construct novel price indices where weights are defined by nutritional criteria, such as achieving sufficient dietary diversity or adequate nutrient intake. Headey and Alderman (2019) use the ICP price data to measure the caloric costs of different foods relative to an index of the cost of a composite staple food calorie in a country. This measure captures how costly it is to diversify diets away from staples, but it also has the virtue of being a currency-free ratio, thereby circumventing problems of exchange rates and purchasing power parity conversion.

Price data are potentially very powerful tools for understanding the (mis)functioning of markets and consumer behavior. As noted above, price data can be used to estimate the affordability of individual foods as well as whole diets, but they can also be used to explore consumer demand for different foods and the impacts of price shocks (Tiberti and Tiberti 2018), seasonality issues (Gilbert, Christiaensen, and Kaminhsk 2017), secular trends in food affordability (Wiggins and Keats 2015; Bachewe and Headey 2016), and integration across markets (Van Campenhout 2007). However, many previous studies using price data to examine these issues have focused on prices of staple foods or consumer prices as a whole, rather than prices of nutrient-dense foods or costs of nutritious diets. In light of the utility of price data for addressing important research questions on agriculture-nutrition linkages, it is surprising that there is not a larger body of research using these data.

\section{Methods for Analyzing Agriculture-Nutrition Linkages}

However, beyond econometric techniques, economywide simulation models are also now being applied to understand how different agricultural policies can influence both household income and dietary measures such as household calorie supply (Pauw and Thurlow 2010), dietary diversity (Arndt et al. 2017), or disease burdens associated with inadequate diets (Springmann et al. 2016). A key challenge here is reaching consensus on the most appropriate nutritional or dietary measures to incorporate into the simulation models, as well as to 
refine consumer demand systems to more realistically estimate the impacts of income and price changes on diets.

\section{Methodological Limitations of the Literature on Agriculture-Nutrition Linkages}

There are several significant methodological challenges to conducting research on nutrition and agriculture.

First, the experimental trials of various nutrition-sensitive agricultural interventions have been widely critiqued in the literature for their limitations, including small projects and sample sizes lacking statistical power, as well as the fact that many interventions combine agricultural components with nutritional education components, making it difficult to disentangle the mechanisms of impact (Masset et al. 2012; Ruel, Quisumbing, and Balagamwala 2018). Sustainability and scalability of these programs are major concerns. It is also notable that very few of these interventions have been implemented by governments (Hirvonen and Headey 2018). In addition, randomized control trials in the agricultural sector-and economic sectors in general-are fraught with complications, including high degrees of variance induced by idiosyncratic and covariate shocks, as well as seasonality (Barrett and Carter 2010; Rosenzweig and Udry 2016).

Second, the growing body of research linking farm production indicators to household consumption or individual nutrition outcomes is observational and essentially describes associations that may or may not be causal (Jones 2017a; Sibhatu and Qaim 2018). Some authors attempt to engage in quasi-experimental approaches, using agroecological variables as instruments, for example (Dillon, McGee, and Oseni 2015; Hirvonen and Hoddinott 2017), or conducting placebo tests to check for evidence of confounding (Hoddinott, Headey, and Dereje 2015; Choudhury and Headey 2018), but these approaches by no means rule out biases in the derived estimates. More ecological studies of markets, prices, or community characteristics face similar concerns, being largely descriptive (albeit usefully descriptive).

Finally, economywide simulation modeling faces both the aforementioned challenges pertaining to incorporating meaningful nutritional measures into their models, and also significant problems in modeling realistic food demand behaviors. Simulation models have the advantage of offering structural explanations of the linkages between agriculture and nutrition, but their deterministic structure means that outcomes can be sensitive to assumption and modeling procedures that are not always fully transparent. Even so, we feel that more research using these tools is strongly warranted given the potential 
importance of the economywide impacts of agricultural interventions on incomes, prices, and diets.

\section{Agricultural Growth as a Driver of Incomes}

A substantial body of literature explores linkages between income/wealth and child nutrition at both the household and economywide level, and most of it establishes at least moderately strong linkages (Bershteyn et al. 2014). Unsurprisingly, however, the associations between economic growth-typically, changes in gross domestic product (GDP) per capita-and changes in stunting are not as strong as they are for economic growth and poverty reduction, because poverty is definitionally related to the income distribution (Headey 2013a). In contrast, incomes have multiple indirect linkages to nutrition through microeconomic impacts on nutritionally relevant food and nonfood expenditures and through macroeconomic impacts on government expenditures on nutrition-specific and nutrition-sensitive investments (for example, WASH, education, agriculture).

At the household level, analyses of the demand for different foods confirm that people diversify out of staple foods as their income levels rise (Subramanian and Deaton 1996). However, meta-analyses of food demand estimates tend to suggest that households diversify most rapidly into animalsourced foods (ASFs) and unhealthy processed foods, while diversification into fruits, vegetables, and pulses is typically less pronounced (Colen et al. 2017). These stylized results also appear to be true of national food systems, which often diversify only slowly, especially into fruits and vegetables (Choudhury and Headey 2017). We also know that governments in different countries allocate their investments across sectors in different ways. India has experienced rapid economic growth in recent decades but has only recently invested in WASH and community health/nutrition initiatives targeted at young children, which may provide an explanation of the often-weak linkages between growth and nutritional improvement in India. At the same time, the connections between economic growth at the macroeconomic level and improved economic status at the household level may simply be quite weak. Indeed, household incomes and wealth tend to be some of the strongest predictors of nutritional improvement (Haddad et al. 2003; Headey, Hirvonen, and Hoddinott 2017).

The literature cited above therefore establishes at least a moderately strong association between income/wealth and nutrition measures but does not specifically inform us about the role of agriculture. Only a handful of studies 
have specifically addressed the role of agricultural growth in influencing child nutrition. Headey (2013a) disaggregates economic growth into weighted growth in agricultural and nonagricultural value-added and finds no systematic difference in the strength of their associations with stunting, although growth in food production in food-insecure countries is significantly associated with stunting reduction. Another study by Headey and Hoddinott (2016) explores the impact of Bangladesh's late Green Revolution in rice production on linear growth (HAZ) and weight gain (WHZ) among young children, as well as infant and young child feeding (IYCF) indicators, using a panel of districts over 1996-2011. They find that growth in rice yields is significantly associated with weight gain and the earlier introduction of solid foods, but not with stunting or dietary diversity indicators. They suggest that growth in staple food production by itself may have limited impacts on stunting because of weak linkages to the diversification of children's diets. An implication is that diversification of food systems is important for improving nutrition, not just increased productivity of staple foods. Moreover, while improving productivity of staples may itself contribute to diversification through both demand and supply-side effects (for example, grains are an input into livestock production), governments themselves may have a role to play in accelerating diversification of production and consumption.

Although the evidence on the nutritional impacts of agricultural growth is limited, it suggests that agricultural growth may have important nutritional impacts in localities characterized by

1. high levels of basic food insecurity in which many households do not consume sufficient calories, and

2. early stages of structural transformation where most of the poor depend on agriculture for a living, particularly production of staple foods.

The first criterion ensures that increases in calorie availability from growth in staple food production could translate into nutritional improvements before hitting diminishing returns, while the second criterion ensures that agricultural growth has large impacts on the incomes of the poor.

In Figure 10.2 we used multicountry DHS data to illustrate these differences by examining stunting prevalence in Africa south of the Sahara (SSA) and South Asia disaggregated by locality (rural/urban), father's primary occupation (farmers, manual workers, in services, professional), and a simple measure of household wealth (the average number of six assets owned). A fourth dimension is population size as approximated by the share of each DHS 
FIGURE 10.2 Stunting prevalence among children 24-59 months, by location, father's occupation, and asset ownership
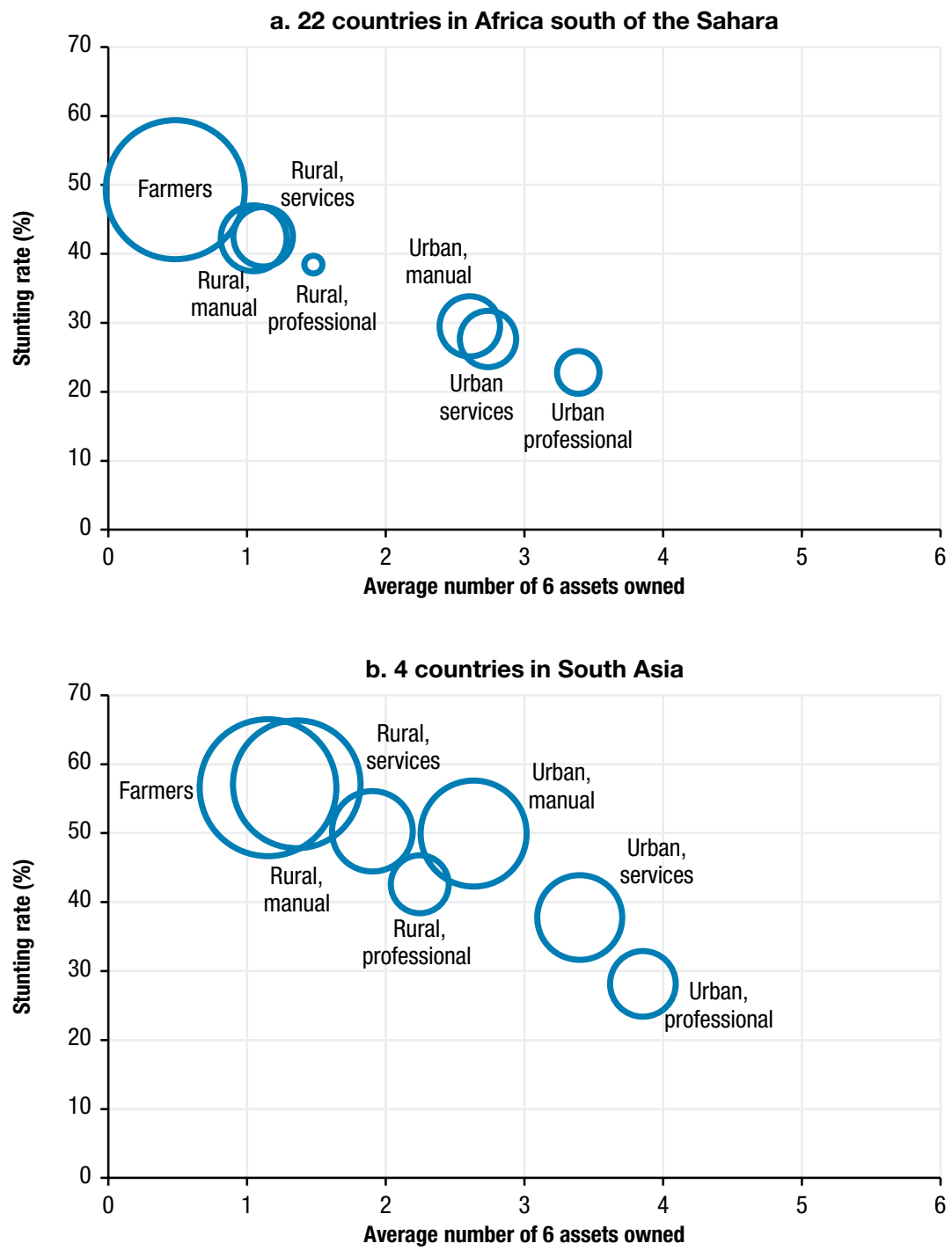

Source: Authors' estimates from Demographic and Health Survey data from Headey, Stifel et al. (2017).

Note: Rural/urban classifications follow the Demographic and Health Survey (DHS) (national) definitions, except that all farming households are classified as rural. Circle sizes reflect the sizes of the samples of children in each locality-occupation class. Ideally this measure should use sample weights, because the DHS oversamples urban areas, but many surveys are several years old, so we do not apply weights, in order to allow for recent urbanization trends. The six assets in question are a TV, motorbike, car, refrigerator, electrification, and an improved floor material. The four countries in South Asia are India, Pakistan, Bangladesh, and Nepal. 
sample classified into a rural-occupation bin. The figure illustrates several striking findings.

First, SSA is still at a relatively early stage of structural transformation, whereas South Asia is at a significantly more advanced stage. In SSA, easily the largest share of children live in households where the father primarily relies on farming for a living, while the rural and urban manual and services occupation clusters all have broadly similar population sizes. In South Asia, more children live in rural nonfarm households (manual work plus services) than in farm households, although the latter group is still sizable. More of the population is also urbanized.

Second, there are very strong associations between locality-occupation categories and household wealth. In SSA farming households are the poorest, but all rural households are substantially poorer than urban households. In South Asia, where landlessness is more common, the wealth difference between farm and nonfarm occupation is not marked, and rural-urban differences in wealth are evident but not as pronounced as they are in SSA.

Third, it is notable that in SSA children of farming households have by far the highest rate of undernutrition, with almost 50 percent stunted in the 24-to-59-month range. Stunting rates are lower for rural nonfarm occupations and substantially lower for more urbanized livelihoods. Overall, however, the association between stunting and wealth is quite pronounced in SSA. In contrast, in South Asia the relationship between stunting rates, occupations, and wealth is more nuanced. Stunting is very high for all rural occupations, but also for urban manual worker households. Indeed, in absolute terms stunting is still very high in urban services and urban professional households.

Overall these findings suggest that agriculture growth is likely to have more impact on stunting in SSA, where stunting is closely associated with poverty, with farming as a livelihood, and with rural living in general. In the more structurally advanced economies of South Asia, the income role of agricultural growth is somewhat more limited.

\section{Food Prices and Nutrition}

\section{Food Price Shocks and Nutrition}

Food affordability has long been viewed as an important linkage between agricultural productivity and poverty, as well as basic food security. Studies of the 2007/2008 global food crisis primarily focused on the impacts of rising prices of staple foods on poverty (Ivanic and Martin 2008) or food security measures 
(Headey 2013b). However, at least one earlier study of the 1998 Indonesian financial crisis showed that rising rice prices can also reduce dietary diversity and increase micronutrient deficiencies, as the real income shock associated with higher rice prices in Indonesia compelled consumers to cut back on more expensive sources of calories, such as eggs (Block et al. 2004).

To assess impacts of food price changes on household expenditure or poverty, economists have typically tried to assess whether consumers are net food consumers or net food producers, following Deaton (1989). Studies conducted after the 2007/2008 crisis often found that many of the poor were net food consumers, even in rural areas (Aksoy and Isik-Dikmelik 2008), suggesting that the poor suffer from higher prices. However, a recent review of these issues highlights two important caveats (Headey and Martin 2016). First, accurate measurement of net food consumption positions is very difficult because of the significant differences in recall periods for consumption and production in household surveys, potentially leading to systematic errors. Second, high food prices typically stimulate increased demand for labor, leading to higher wages and offsetting at least some of the damage of higher prices to nonfarming households.

While the research cited above is relevant to nutrition because of the associations between income/food security, diets, and nutrition outcomes, hardly any rigorous research examines the impacts of price volatility on nutrition outcomes or dietary diversity. This would seem to be an important area for future research.

\section{International Variation in Food Prices and Dietary Affordability}

While food prices are volatile over time, there are also strong theoretical reasons to expect prices to vary across countries, since many foods are not perfectly tradable or are very costly to trade. This is particularly true of highly perishable fruits, vegetables, and ASFs, but much less true for cereals, which are highly traded all over the world. Moreover, since cereals and other staples constitute the largest source of calories for poor populations, it makes sense to ask how costly it is for different populations to diversify away from staples.

Previous research only provides indirect answers to this question. Bennett (1941) provides a classic analysis of the diversification of Western diets away from wheat-based products, while Subramanian and Deaton (1996) show that consumers opt for more-expensive sources of calories as incomes rise. In the United States and Europe obesity researchers have also focused on measuring the costs of different sources of calories, typically noting that unhealthy processed foods (such as soft drinks) are much cheaper than healthy fresh foods 


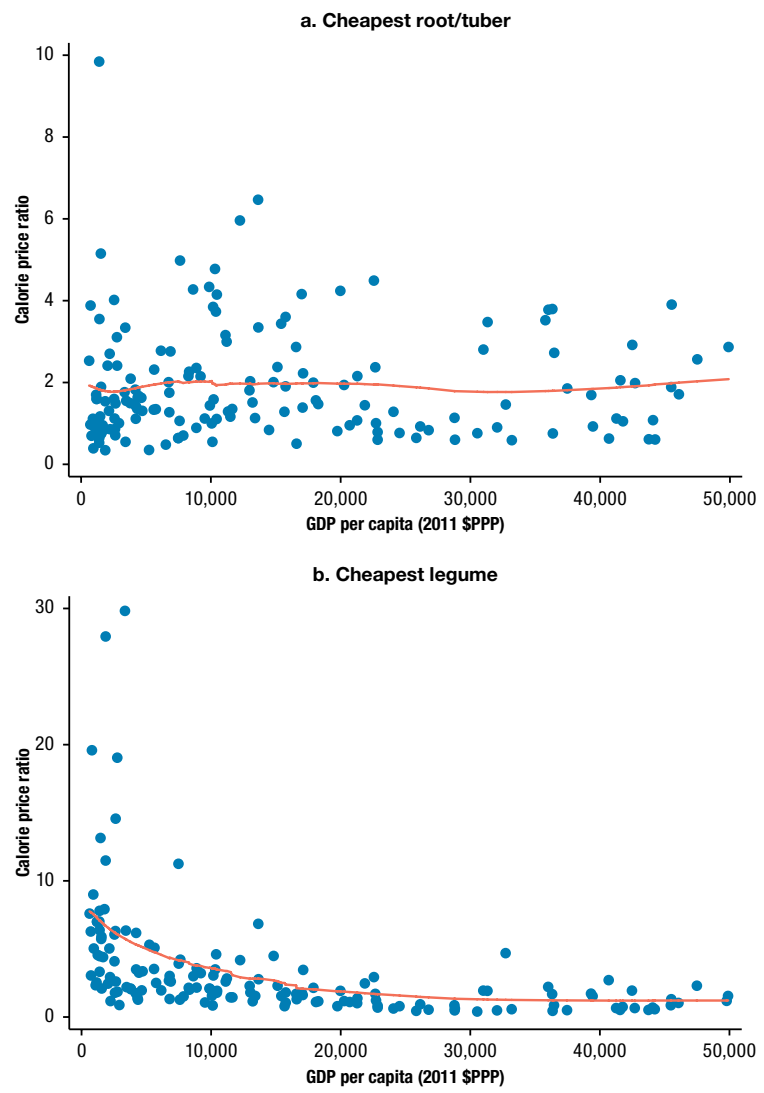

in caloric terms (Darmon and Drewnowski 2015). A recent study provides a more extensive quantification of the caloric costs of 657 different foods in 176 countries but measures each nonstaple food's caloric cost relative to that of a basket of country-specific staple foods (Headey and Alderman 2019). These relative caloric prices are therefore currency-free ratios that measure the costliness of diversifying away from the cheapest staple in any given country.

The results of that study reveal that prices of different foods are highly variable across countries and across different income levels, particularly for less tradable products such as eggs, fresh milk, and some (but not all) fresh fruits and vegetables. Figures 10.3 and 10.4 show scatter plots of these calorie price ratios against GDP per capita for the seven food groups listed in Table 10.2 and fortified infant cereals (which are a potential alternative means 


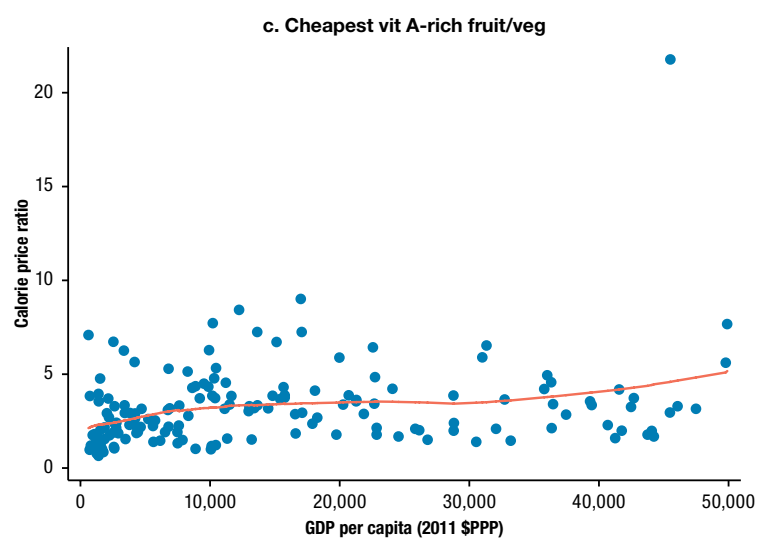

d. Cheapest other fruit/veg

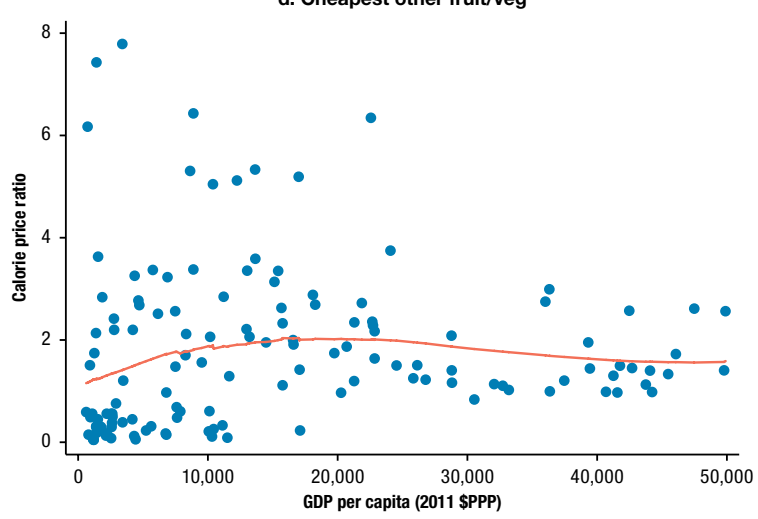

Source: Data are from Headey and Alderman (2019).

Note: GDP = gross domestic product; \$PPP = purchasing power parity dollars. Red lines show LOWESS curves to allow for nonlinear functional forms.

of diversifying the diet with a complete range of essential nutrients). In this large sample of countries, per capita income varies from just $\$ 617$ per capita in the Democratic Republic of Congo to approximately $\$ 50,000$ per capita in the United States.

The results reveal several important findings.

First, among vegetal foods (Figure 10.3), legumes/nuts are a cheap source of calories (and typically the cheapest source of protein), but dark green leafy vegetables, vitamin A-rich fruits and vegetables, and other fruits/vegetables are relatively expensive. Interestingly, though, some vegetal foods tend to be more expensive in higher-income countries (especially dark green leafy vegetables), although in poor countries there is also substantial variation in relative caloric prices. 
FIGURE 10.4 Relative caloric prices for various animal-sourced foods and fortified infant cereals
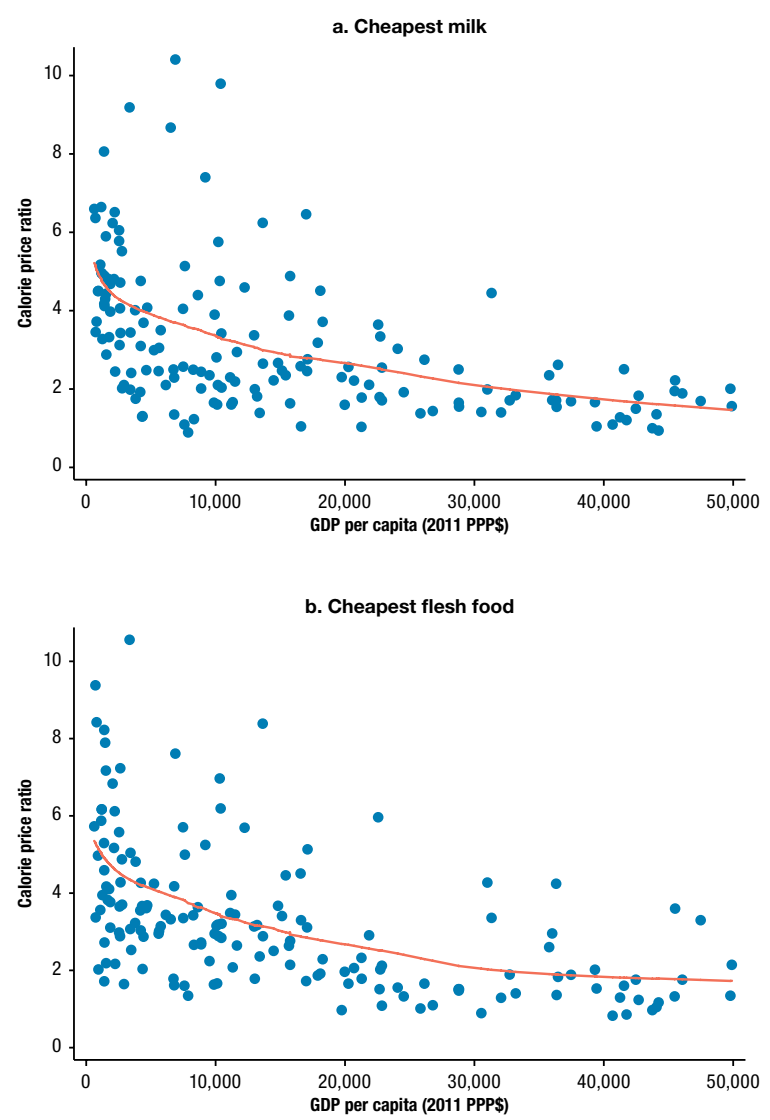

Second, dairy, eggs, and fortified infant cereals show a very different pattern (Figure 10.4), with very high prices in poorer countries (on average) that decline as incomes rise. Indeed, in many of the poorest countries, calories from milk, eggs, and fortified cereals are 10 times as expensive as calories from staple foods. Headey and Alderman (2019) also show that dairy prices, in particular, are robustly and positively associated with stunting rates across countries, meaning that the high cost of dairy might offer an important explanation of high stunting rates in Africa and Asia especially. In contrast to these other ASFs, meat (red or white) tends to be cheaper, with a much weaker income gradient, while fish (not shown in the table) is relatively cheap in Southeast Asia and western and central Africa where it is widely consumed. 

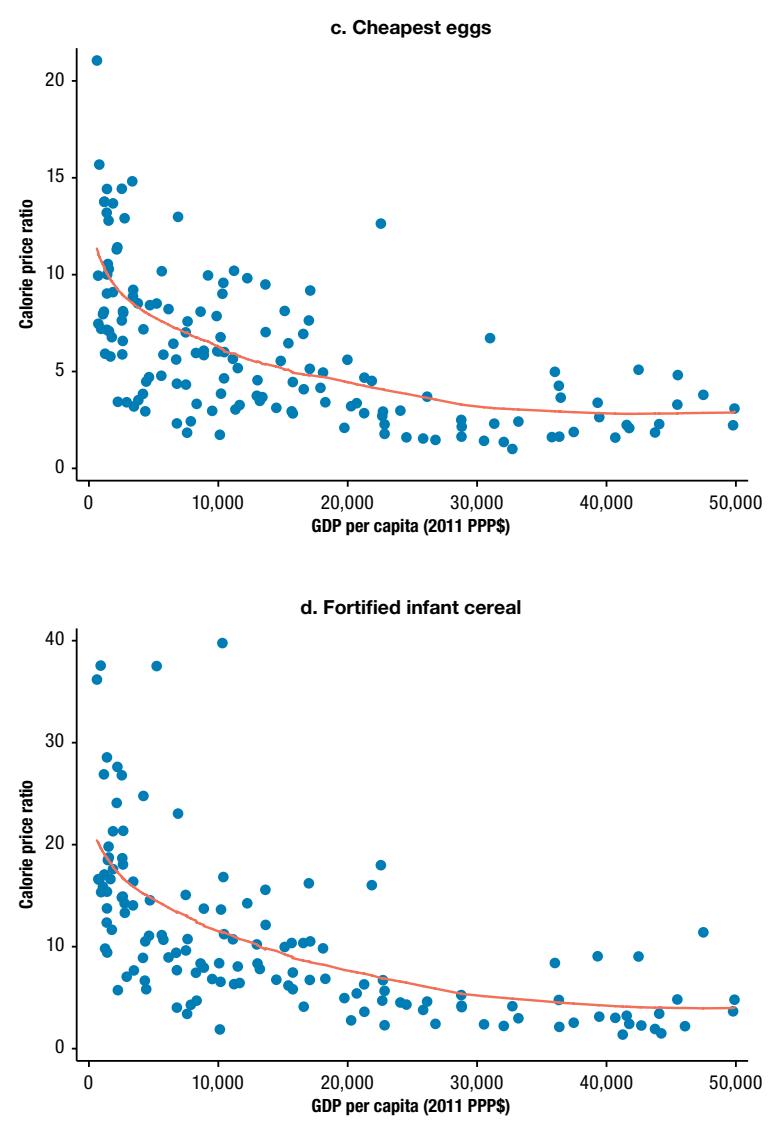

Source: Data are from Headey and Alderman (2019).

Note: GDP = gross domestic product; PPP\$ = purchasing power parity dollars. Red lines show LOWESS curves to allow for nonlinear functional forms.

The variation in relative prices across countries is stark, but in several respects not surprising. First, the relative caloric prices across countries partly reflect variation in the denominator (the cost of staple foods, which rise as incomes rise because consumers choose more expensive staple foods when their incomes rise). Second, perishability and tradability clearly explain some of these patterns. Fresh milk and eggs are extreme cases of food products that are difficult to trade long distances (especially in countries with underdeveloped value chains), so the prices of these products are largely determined by productivity levels in the domestic dairy and poultry sectors, which are generally low in poorer countries. Finally, fortified infant cereals are highly tradable products but still extremely expensive in lower-income countries because they 
are informational goods: parents have little trust in locally produced infant cereals and instead opt for very expensive multinational brands if they can afford them (Masters, Nene, and Bell 2017).

These findings suggest that an important objective of nutrition-sensitive agricultural investments and reforms should be making nutrient-dense foods more affordable. This could stem from productivity investments in "nontradable" sectors (for example, poultry or fresh milk), but also by addressing trade distortions that limit imports of nutrient-dense foods (for example, dairy powder).

\section{Shadow Prices and Missing Markets for Nutritious Foods}

The section above describes cross-country variation in prices, but there is also an extensive literature on the variation of implicit "shadow" prices within countries. Shadow prices are the implicit values or opportunity costs that households face when trying to obtain additional quantities of something for which an explicit price does not exist because of missing or incomplete markets. Markets might fail to provide an adequate supply of all foods throughout the year because of perishability_-particularly of eggs, fresh milk, and many fruits and vegetables_-and because local demand for these products is quite limited in low-income and low-density rural populations. Faced with imperfect supply from markets, households make production decisions that are designed to satisfy their consumption demands. For example, in Ethiopia over 90 percent of the milk produced by rural households is consumed by those same households (Hoddinott, Headey, and Dereje 2015). In this situation there are, unsurprisingly, strong associations between cattle ownership and children's milk consumption, but also between cattle ownership and child growth outcomes. Many other studies have linked livestock ownership to increased consumption of ASFs (Kabunga, Ghosh, and Webb 2017; Choudhury and Headey 2018) and local crop diversity to dietary diversity (Dillon, McGee, and Oseni 2015; Jones 2017b; Sibhatu and Qaim 2018).

In Figure 10.5 we report summary results from a multivariate regression analysis of an extensive multicountry synthetic dataset combining DHS surveys with geographic information system (GIS) data on agroecological characteristics and a "market access" indicator of travel times to markets (Heady, Nguyen et al. 2017). The figure shows the sign (+/-) and strength of each association with the goal of uncovering broad patterns of associations. For household-level factors from the DHS, we observe the expected strong and positive relationship between wealth and most dietary indicators, with vitamin A-rich fruits and vegetables and legumes/nuts being the sole exceptions, 
FIGURE 10.5 Associations between children's food consumption patterns and various household (DHS) and community characteristics (GIS)

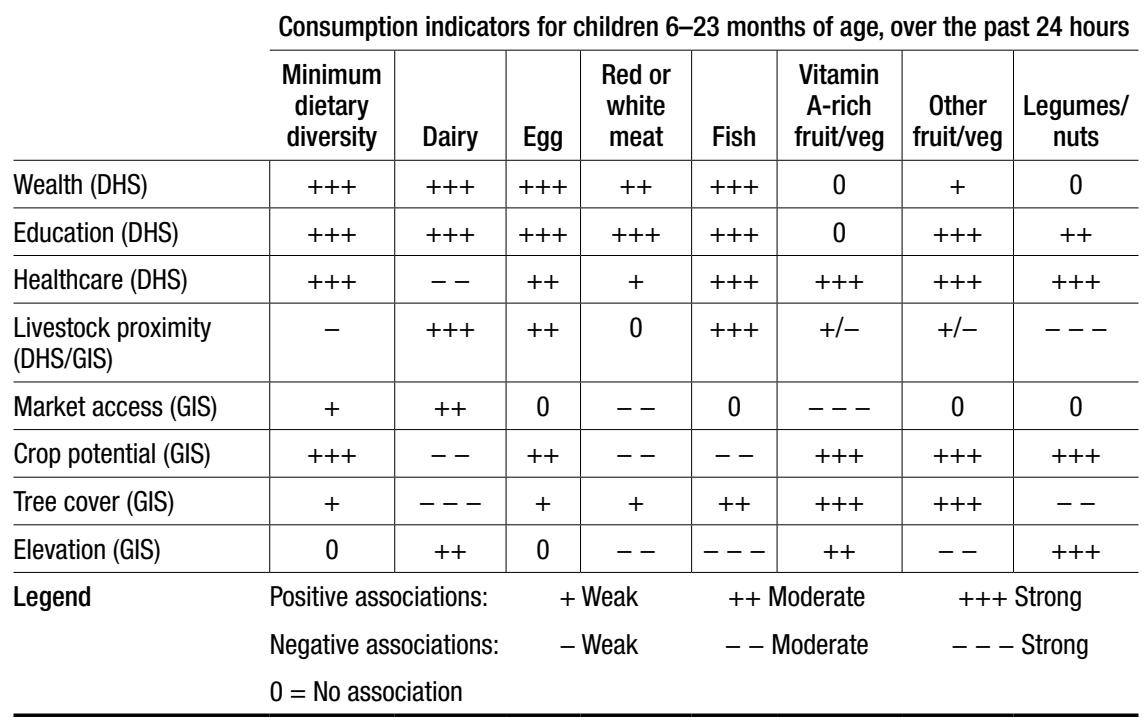

Source: Authors' estimates from a multicountry dataset linking DHS surveys to GIS indicators (Headey, Stifel et al. 2017). Note: DHS = Demographic and Health Surveys; GIS = geographic information system.

suggesting these may be inferior goods. Similar patterns hold for parental education and access to healthcare. Of greater interest is the importance of community characteristics. Livestock proximity (ownership of livestock or proximity to fisheries at major lakes and rivers) is strongly associated with dairy, poultry, and fish consumption, but not with red or white meat consumption. A market access indicator-estimated travel time to 25,000-person cities-is associated with aggregate dietary diversity and with dairy consumption but has insignificant or negative associations with consumption of other foods. Crop potential is strongly and positively associated with minimum dietary diversity, egg consumption, and consumption of crop-based foods, while tree cover is generally also associated with consumption of most foods (see Johnson, Brown, and Jacob 2013 for a detailed study on this relationship). Elevation is associated with increased dairy consumption, which is unsurprising given the reduction in livestock diseases at higher altitudes, but has mixed associations with other variables. Another recent study explores these kinds of associations in multivariate regression models and shows that child dietary patterns are significantly related to environmental characteristics, even after controlling for individual and household characteristics. However, 
the magnitude of the associations is often moderate, consistent with a recent meta-analysis of farm-level studies finding generally modest links between production diversity and dietary diversity.

Another recent study links data on farm production, community production, and the availability and cost of different foods in local markets in poor rural areas of Ethiopia (Headey et al. 2019). As was the case with more aggregate price data, these authors show that ASFs and fruits and vegetables are generally very expensive in rural markets, while dairy is not sold in approximately half of the markets surveyed but is instead own-consumed or sourced from neighbors. Their results paint a somewhat complex picture: ownconsumption is not overwhelmingly important except in the case of dairy, but markets were also incapable of providing nutrient-dense foods at an affordable price. A large analysis of food sources in Ethiopia shows that households predominantly rely on markets to source nonstaple foods (except dairy), suggesting that markets are important. But while these studies are interesting, there are remarkably few studies examining food markets in developing countries through a nutritional lens, and much more work is needed on this front.

\section{Agriculture, Rural Livelihoods, and Nutrition}

\section{Rural Poverty and Limited Access to Infrastructure and Services}

As we saw in Agricultural Growth as a Driver of Incomes, stunting rates and absolute numbers of stunted children are significantly higher in rural areas of SSA than in urban areas. Figure 10.2 also provided at least one explanation of this phenomenon: rural people are simply poorer than urban people, as measured by household assets. However, wealth differences provide only one likely explanation of the nutritional disadvantages of rural populations, since there are many other dimensions of rural living that might also contribute to undernutrition. Earlier research concluded that this rural-urban inequality in nutritional status stemmed from differences in "endowments" - such as wealth, education, and access to services-rather than from the nutritional returns to these endowments (Smith, Ruel, and Ndiaye 2004; Zanello, Srinivasen, and Shankar 2016). A recent paper extended this research for a broader range of SSA countries to examine both rural-urban differences and differences across different degrees of remoteness based on proximity to 25,000-person cities (Headey, Nguyen et al. 2017). Strikingly, the results imply that proximity to cities is not important independent of its associations with wealth, education, and access to services. Instead, remote villages—and rural villages 
in general-are simply characterized by poverty, low levels of human capital, and poor access to services. Indeed, these authors extend the rural-urban decompositions of earlier work to find that differences in endowments explain 77 percent of the observed difference in stunting rates across rural and urban areas, with differences in socioeconomic status (wealth and nonfarm employment) accounting for almost 40 percent of this difference, followed by parental education (19 percent) and health/infrastructural services (11 percent). They also find similar results for rural-urban differences in child dietary diversity. An implication of these results is that physical remoteness seems to primarily influence nutrition through its harmful impacts on multidimensional poverty.

A related strand of literature looks at "nutrition smoothing" to identify how access to markets, local infrastructure, and public services helps households buffer the impacts of nutritional shocks (Mulmi et al. 2016; DarrouzetNardi and Masters 2017; Shively 2017; Thapa and Shively 2018). The specific kind of shock most often investigated is seasonal fluctuations in rainfall and temperature around the time of a child's birth, which is much more closely linked to attained height for children in poorer, more remote places than in towns and cities. Some of the apparent link between month of birth and height for age is due to random errors in recorded birth months among children without birth registrations (Larsen, Headey, and Masters 2019), but even after adjusting for those errors, there is significant variation in attained height by season of birth (Finaret and Masters 2019). Research to date has shown how sanitation, food markets, and local infrastructure can help households protect their children from seasonal climate fluctuations (Mulmi et al. 2016; Shively 2017; Thapa and Shively 2018), leading to new work focusing on specific kinds of smoothing such as year-round access to a nutritious diet (Bai, Naumova, and Masters 2019).

\section{Agricultural Production Hazards}

Beyond problems with remoteness and poor access to services, most rural populations still primarily work in agriculture, which presents its own potential health and nutritional hazards. A mostly qualitative literature, particularly in South Asia, has explored associations between women's employment in agriculture and maternal nutrition, including substantial workloads during and soon after pregnancy (Balagamwala et al. 2015). One important concern is that physical exertion-especially in conditions of high temperatures-may be harmful for women's nutrition, including during pregnancy or lactation. 
This literature also expresses concerns about the impacts of women's workload and time constraints on their ability to care for children and attain diverse diets (Johnston et al. 2018; Stevano et al. 2019). There is some evidence, for example, that agricultural interventions can increase women's workloads and time constraints, although there are few clear and consistent relationships to nutrition outcomes, perhaps because different household members respond in different ways or because income gains from agricultural intensification offset time constraints. Overall, though, there is little solid empirical evidence on whether agricultural employment is harmful to maternal or child nutrition beyond the obvious associations between employment in agriculture and general socioeconomic poverty.

Other research has examined specific biological mechanisms linking agricultural livelihoods to health. For example, Brainerd and Menon (2014) look at the long-standing concern that excess and inappropriate use of chemical inputs, particularly pesticides and herbicides, has harmful effects on health and nutrition. They find significant evidence of adverse impacts on maternal and child health, including birthweight. More recently, Sheahan, Barrett, and Goldvale (2017) examine pesticide use in five SSA countries and find that pesticide use is associated with greater health expenditures and more sick days, although they do not test associations with child nutrition outcomes.

Another strand of research has looked at health problems associated with livestock ownership. Formative research in a rural Zimbabwean village monitored children for 12-hour periods (Ngure et al. 2013). They found that a large proportion of children directly consumed or mouthed chicken feces and dirt that may have been contaminated with chicken feces. They also show that the bacterial loads of chicken feces are some 10,000 times higher than dirt and other surfaces in the household. They argue that ingestion of such high loads of bacteria may contribute to environmental enteropathy, a chronic but latent infection of the gut that has been strongly linked to child stunting. Subsequent research in Ethiopia (Headey and Hirvonen 2016) and Bangladesh (George et al. 2015) found that children living under the same roof as poultry were more likely to be stunted, and a three-country study by Headey, Hoddinott, and Park (2017) found that homesteads in Bangladesh and Ethiopia with observable animal feces in the compound had shorter children. A systematic review of diarrheal studies also found significant associations with livestock ownership in a majority of studies (Zambrano et al. 2014). Hence, despite the importance of ASF intake for child nutrition, and the clear associations between livestock ownership and ASF consumption, there are also negative pathways between livestock ownership and child growth. These 
pathways presumably operate mainly through fecal contamination and enteric infections, though pulmonary infections associated with poultry ownership are a potential concern (Gomaa et al. 2015), as is the connection between cattle ownership and malaria (Donnelly et al. 2015).

\section{Implications for Policy and Research}

Historical and comparative evidence suggests there are three main levers by which agricultural change and food policy influence diets and nutrition outcomes.

The first lever of agriculture's influence is through growth in real incomes and poverty reduction. Agricultural growth-including growth in staple food production-has been shown to be a historically important driver of poverty reduction because so many poor people directly and indirectly depend on agriculture for a living (Diao, Hazell, and Thurlow 2010). Evidence reported above suggests that agricultural growth is still likely to be an important driver of poverty reduction in South Asia and SSA, though much more so in the latter. Of course, whether agricultural investments offer the most-effective means of reducing poverty is another question (Dercon and Gollin 2014). Moreover, admittedly scant empirical evidence from Bangladesh (Headey and Hoddinott 2016) suggests that the nutritional benefits of cereals-oriented agricultural development strategies may be limited, because rapid increases in consumption of more nutrient-dense foods is not guaranteed by productivity growth in cereals. More research is needed on this issue, however.

The second lever is through influencing the relative price of nutritious foods and managing food price variation. Evidence from different settings suggests that urbanization, infrastructure, or market access or all of those may suppress various nutritional insults. And though not well documented, it is likely that market development plays an important role in reducing both average prices and price fluctuations. Recent research on relative price differences across countries emphasizes the imperfect tradability of nutrient-dense foods, including ASFs that may be critical for healthy growth and cognitive development in early childhood. This suggests that in many localities certain nutrientrich foods are either not affordable or not accessible in the market, forcing farmers into potentially inefficient self-reliance. The costliness of highly nutritious foods in lower-income countries perhaps provides the strongest mandate for nutrition-focused agricultural development; other economic sectors may well drive income growth, but only food policies can influence the affordability of nutritious foods. 
The third agricultural lever for nutrition is through the transformation of agricultural livelihoods. In developing countries rural populations pervasively have nutrition outcomes that are significantly worse than urban populations, and there is little mystery as to why this is so: rural populations are much poorer and have substantially less access to essential goods and services. Yet they also face specific hazards associated with agricultural living, including exposure to potentially harmful chemical inputs, physically arduous work (including mothers), and highly unhygienic environments due to poor livestock management practices.

What are the policy implications of these findings? More specifically, what should agricultural development actors do differently, if they care about nutrition?

First, agricultural policy instruments should still be used to improve incomes of rural populations, but they should also be used to reduce the prices of nutritionally important foods. These include ASFs of importance to young children (dairy, eggs, fish), as well as fresh fruits and vegetables. This might entail alterations in the portfolio of agricultural investments toward nonstaple foods, both in international organizations (such as CGIAR) and national research and implementation agencies. We estimate that at least 80 percent of CGIAR expenditures are allocated to crops-and many of these are starchy staples—and just 20 percent are allocated to livestock and fisheries, and we suspect that in many developing countries these ratios are even more skewed in favor of staple crops. Arguably this is a lopsided composition. However, it is also crucial to better understand the important role of cereals and soybeans as feed inputs into the livestock and aquaculture sectors. High feed costs in Africa, in particular, may offer one explanation as to why many ASFs remain prohibitively expensive there (Andam, Arndt, and Hartley 2017).

Beyond the composition of public investment, however, the development of higher-value sectors also entails a greater role for the private sector and public-private partnerships, including working with larger and more commercialized farms and firms. Nutritionally important foods are highly perishable (unlike staple cereals), meaning that value-chain bottlenecks are often binding constraints, including poor infrastructure and storage. Lengthier value chains involve many more private sector actors such as wholesalers, traders, and retailers. There are also important economies of scale for some high-value sectors, meaning that larger firms are a more efficient structure for achieving rapid productivity growth and larger reductions in prices for consumers (particularly poultry). There are also opportunities to use trade as an instrument for reducing the prices of nonperishable nutrient-rich foods. Many meat 
products are highly tradable when frozen or dried, while dairy powder is also highly tradable and relatively affordable but underconsumed in many lowincome countries. Hence, efforts to improve consumption of nutrient-rich foods do not need to solely rely on production, especially for products in which the country has little or no comparative advantage. This will likely be the case for dairy production in most tropical countries, and East Asian experience has been instructive in this regard through its combination of trade and investment in the domestic dairy sector (FAO 2008).

Second, policies need to focus more holistically on the health implications of farming as a livelihood. One of the most persistent problems for rural populations has been access to nutritionally important goods and services, including education, basic maternal and child health services, and WASH. This is likely a combination of the high cost of extending these services to remote and dispersed rural populations (especially in Africa), urban-biased political systems, and various governance problems such as corruption and insufficient decentralization (Headey, Bezemer, and Hazell 2010). In recent times some countries have made impressive strides in extending basic services to remote rural communities (Global Health Workforce Alliance 2013), with Nepal being an exemplar in this regard. But for agricultural households, specifically, there are farming-related health hazards that have long been neglected, including inappropriate use of chemical inputs (Sheahan, Barrett, and Goldvale 2017), scavenging livestock systems combined with poor household hygiene (Headey and Hirvonen 2016), and (one suspects) excessively high workloads for women in general and mothers in particular.

In truth, we still know relatively little about the importance of these farm-level hazards for human nutrition, or how policies can most effectively combat them. Nevertheless, policymakers cannot always wait on rigorous evidence, and there is a strong case to be made for multisectoral policies designed to reduce the health hazards associated with agricultural livelihoods. This includes regulations and agricultural extension practices designed to reduce the health hazards associated with inappropriate chemical input use, integrated agriculture-WASH programs to reduce fecal contamination by livestock (for example, community hygiene, improved poultry housing, increased awareness), and integrated programs that combine social protection, nutrition, and agriculture to reduce women's workloads, especially during and soon after pregnancy.

In recent years our understanding of agriculture-nutrition linkages has vastly improved, but many knowledge and policy gaps remain. Much more emphasis is needed on how policies influence diets through income and price changes, what trade-offs may exist between poverty and nutrition targets, and 
on how multisectoral rural development efforts can improve access to basic services and reduce farming's hidden health risks.

\section{References}

Aksoy, M. A., and A. Isik-Dikmelik. 2008. Are Low Food Prices Pro-Poor? Net Food Buyers and Sellers in Low-Income Countries. Policy Research Working Paper 4642. Washington, DC: World Bank.

Alderman, H., and D. Headey. 2017. “The Timing of Growth Faltering Has Important Implications for Observational Analyses of the Underlying Determinants of Nutrition Outcomes." In Stunting: Past, Present and Future. London: London School of Economics and Political Science.

Alkire, S., R. Meinzen-Dick, A. Peterman, A. Quisumbing, G. Seymour, and A. Vaz. 2012. The Women's Empowerment in Agriculture Index. IFPRI Discussion Paper 1240. Washington, DC: IFPRI.

Andam, K. S., C. Arndt, and F. Hartley. 2017. Eggs Before Chickens? Assessing Africa's Livestock Revolution with an Example from Ghana. IFPRI Discussion Paper 1687. Washington, DC: IFPRI.

Arndt, C., et al. 2017. "Measuring Household Diet Quality: Revisiting the 'Diet Problem.”' Unpublished. IFPRI, Washington, DC.

Bachewe, F., and D. Headey. 2016. "Urban Wage Behaviour and Food Price Inflation in Ethiopia." Journal of Development Studies 53 (8): 1-16.

Bai, Y., E. Naumova, and W. Masters. 2019. Seasonality in the Cost of Nutritious Diets in Malawi, Tanzania and Ethiopia. CANDASA project working paper. Medford, MA: Tufts University.

Balagamwala, M., H. Gazdar, and H. B. Mallah. 2015. Women's Agricultural Work and Nutrition in Pakistan: Findings from Qualitative Research. Working Paper 2. Leveraging Agriculture for Nutrition in South Asia (LANSA).

Barrett, C. B., and M. R. Carter. 2010. "The Power and Pitfalls of Experiments in Development Economics: Some Non-Random Reflections.” Applied Economic Perspectives and Policy 32: 515-548.

Bennett, M. 1941. "Wheat in National Diets." Wheat Studies 18: 37-76.

Bershteyn, A., H. Lyons, D. Sivam, and N. Myhrvold. 2014. "Association between Economic Growth and Early Childhood Nutrition." Lancet Global Health 3: e79-e80.

Block, S., L. Kiess, P. Webb, S. Kosen, R. Moench-Pfanner, M. Bloem, and C. P. Timmer. 2004. "Macro Shocks and Micro Outcomes: Child Nutrition during Indonesia’s Crisis." Economics and Human Biology 2: 21-44. 
Brainerd, E., and N. Menon. 2014. "Seasonal Effects of Water Quality: The Hidden Costs of the Green Revolution to Infant and Child Health in India." Journal of Development Economics 107: 49-64.

- 2017. "What Drives Diversification of National Food Supplies?

A Cross-Country Analysis." Global Food Security 15: 85-93.

_ 2018. "Household Dairy Production and Child Growth: Evidence from Bangladesh." Economics \& Human Biology 30: 150-161.

Darmon, N., and A. Drewnowski. 2015. "Contribution of Food Prices and Diet Cost to Socioeconomic Disparities in Diet Quality and Health: A Systematic Review and Analysis." Nutrition Reviews 73: 643-660.

Darrouzet-Nardi, A. F., and W. A. Masters. 2017. "Nutrition Smoothing: Can Proximity to Towns and Cities Protect Rural Children against Seasonal Variation in Agroclimatic Conditions at Birth?” PLOS ONE 12: e0168759.

Deaton, A. 1989. "Rice Prices and Income Distribution in Thailand: A Non-Parametric Analysis." Economic Journal 99: 1-37.

de Janvry, A., M. Fafchamps, and E. Sadoulet. 1991. "Peasant Household Behavior with Missing Markets: Some Paradoxes Explained." Economic Journal 101: 1400-1417.

Dercon, S., and D. Gollin. 2014. "Agriculture in African Development: Theories and Strategies." Annual Review of Resource Economics 6: 471-492.

Diao, X., P. Hazell, and J. Thurlow. 2010. “The Role of Agriculture in African Development.” World Development 38: 1375-1383.

Dillon, A., K. McGee, and G. Oseni. 2015. "Agricultural Production, Dietary Diversity and Climate Variability." Journal of Development Studies 51: 976-995.

Donnelly, B., L. Berrang-Ford, N. Ross, and P. Michel. 2015. "A Systematic, Realist Review of Zooprophylaxis for Malaria Control." Malaria Journal 14: 313.

FANTA (Food and Nutrition Technical Assistance). 2006. Developing and Validating Simple Indicators of Dietary Quality and Energy Intake of Infants and Young Children in Developing Countries: Summary of Findings from Analysis of 10 Data Sets. Washington, DC: FANTA and FHI.

FAO (Food and Agriculture Organization of the United Nations). 2008. Improved Market Access and Smallholder Dairy Farmer Participation for Sustainable Dairy Development: Asia Smallholder Dairy Development Strategy and Outline Investment Plan. Rome.

Finaret, A. B., and W. A. Masters. 2019. "Correcting for Artifactual Correlation between Misreported Month of Birth and Attained Height-for-Age Reduces but Does Not Eliminate Measured Vulnerability to Season of Birth in Poorer Countries." American Journal of Clinical Nutrition 110: 485-497. 
George, C. M., L. Olja, S. Biswas et al. 2015. "Fecal Markers of Environmental Enteropathy Are Associated with Animal Exposure and Caregiver Hygiene in Bangladesh." American Society of Tropical Medicine and Hygiene 93: 269-275.

Gilbert, C. L., L. Christiaensen, and J. Kaminhski. 2017. “Food Price Seasonality in Africa: Measurement and Extent." Food Policy 67: 119-132.

Girard, A. W., J. Self, C. McAuliffe, and O. Olude. 2012. “The Effects of Household Food Production Strategies on the Health and Nutrition Outcomes of Women and Young Children: A Systematic Review." Paediatric and Perinatal Epidemiology 26: 205-222.

Global Health Workforce Alliance. 2013. Global Experience of Community Health Workers for Delivery of Health Related Millennium Development Goals: A Systematic Review, Country Case Studies, and Recommendations for Integration into National Health Systems. World Health Organization.

Gomaa, M. R., A. Kayed, M. Elabd et al. 2015. “Avian Influenza A(H5N1) and A(H9N2) Seroprevalence and Risk Factors for Infection among Egyptians: A Prospective, Controlled Seroepidemiological Study." Journal of Infectious Diseases 211: 1399-1407.

Haddad, L., H. Alderman, S. Appleton, L. Song, and Y. Yohannes. 2003. "Reducing Child Malnutrition: How Far Does Income Growth Take Us?” World Bank Economic Review 17: $107-131$.

Haselow, N. J., A. Stormer, and A. Pries. 2016. “Evidence-Based Evolution of an Integrated Nutrition-Focused Agriculture Approach to Address the Underlying Determinants of Stunting." Maternal \& Child Nutrition 12 (Suppl. 1): 155-168.

Headey, D. 2013a. "Developmental Drivers of Nutritional Change: A Cross-Country Analysis." World Development 42: 76-88.

_. 2013b. "The Impact of the Global Food Crisis on Self-Assessed Food Security." World Bank Economic Review 27: 1-27.

Headey, D. , and H. Alderman. 2019. "The Relative Caloric Prices of Healthy and Unhealthy Foods Differ Systematically across Income Levels and Continents." Journal of Nutrition 149 (11): 2020-2033.

Headey, D., D. Bezemer, and P. Hazell. 2010. “Agricultural Employment Trends in Asia and Africa: Too Fast or Too Slow?” World Bank Research Observer 25: 57-89.

Headey, D., A. Chiu, and S. Kadiyala. 2012. “Agriculture's Role in the Indian Enigma: Help or Hindrance to the Crisis of Undernutrition?” Food Security 4: 87-102.

Headey, D., and K. Hirvonen. 2016. "Is Exposure to Poultry Harmful to Child Nutrition? An Observational Analysis for Rural Ethiopia.” PLOS ONE 11: e0160590. 
Headey, D., K. Hirvonen, and J. Hoddinott. 2017. Animal Sourced Foods and Child Stunting. IFPRI Discussion Paper 1695. Washington, DC: IFPRI.

Headey, D., K. Hirvonen, J. Hoddinott, and D. Stifel. 2019. "Rural Food Markets and Child Nutrition." American Journal of Agricultural Economics 101 (5): 1311-1327.

Headey, D., and J. Hoddinott. 2016. “Agriculture, Nutrition and the Green Revolution in Bangladesh." Agricultural Systems 149: 122-131.

Headey, D., J. Hoddinott, and S. Park. 2017. "Accounting for Nutritional Changes in Six Success Stories: A Regression-Decomposition Approach." Global Food Security 13: 12-20.

Headey, D., and W. J. Martin. 2016. "Food Prices, Poverty, and Food Security." Annual Review of Resource Economics 8: 329-351.

Headey, D., P. Nguyen, S. Kim, R. Rawat, M. Ruel, and P. Menon. 2017. “Is Exposure to Animal Feces Harmful to Child Nutrition and Health Outcomes? A Multicountry Observational Analysis." American Journal of Tropical Medicine and Hygiene 96: 961-969.

Headey, D., D. Stifel, L. You, and Z. Guo. 2017. Remoteness, Urbanization and Child Nutrition in Sub-Saharan Africa. IFPRI Discussion Paper 1694. Washington, DC: IFPRI.

Hirvonen, K., and D. Headey. 2018. "Can Governments Promote Homestead Gardening at Scale? Evidence from Ethiopia.” Global Food Security 19: 40-47.

Hirvonen, K., and J. Hoddinott. 2017. “Agricultural Production and Children’s Diets: Evidence from Rural Ethiopia.” Agricultural Economics 48: 469-480.

Hoddinott, J. 2011. Agriculture, Health and Nutrition: Conceptualizing the Linkages, Leveraging Agriculture for Improving Nutrition and Health. New Delhi: IFPRI.

Hoddinott, J., D. Headey, and M. Dereje. 2015. "Cows, Missing Milk Markets, and Nutrition in Rural Ethiopia.” Journal of Development Studies 51: 958-975.

Ivanic, M., and W. Martin. 2008. "Implications of Higher Global Food Prices for Poverty in Low-Income Countries." Agricultural Economics 39 (S1): 405-416.

Johnson, K. B., M. E. Brown, and A. Jacob. 2013. "Forest Cover Associated with Improved Child Health and Nutrition: Evidence from the Malawi Demographic and Health Survey and Satellite Data." Global Health: Science and Practice 1 (2): 237.

Johnston, D., S. Stevano, H. Malapit, E. Hull, and S. Kadiyala. 2018. "Review: Time Use as an Explanation for the Agri-Nutrition Disconnect: Evidence from Rural Areas in Low and Middle-Income Countries." Food Policy 76: 8-18.

Jones, A. D. 2017a. "Critical Review of the Emerging Research Evidence on Agricultural Biodiversity, Diet Diversity, and Nutritional Status in Low- And Middle-Income Countries." Nutrition Reviews 75: 769-782. 
. 2017b. "On-Farm Crop Species Richness Is Associated with Household Diet Diversity and Quality in Subsistence- and Market-Oriented Farming Households in Malawi." Journal of Nutrition 147: 86-96.

Kabunga, N. S., S. Ghosh, and P. Webb. 2017. “Does Ownership of Improved Dairy Cow Breeds Improve Child Nutrition? A Pathway Analysis for Uganda." PLOS ONE 12: e0187816.

Kadiyala, S., J. Harris, D. Headey, S. Yosef, and S. Gillespie. 2014. "Agriculture and Nutrition in India: Mapping Evidence to Pathways." Annals of the New York Academy of Sciences 1331: $43-56$.

Larsen, A. F., D. Headey, and W. Masters. 2019. "Misreporting Month of Birth: Diagnosis and Implications for Research on Nutrition and Early Childhood in Developing Countries." Demography 56: 707-728.

Leroy, J. L., and E. A. Frongillo. 2007. "Can Interventions to Promote Animal Production Ameliorate Undernutrition?" Journal of Nutrition 137: 2311-2316.

Masset, E., L. Haddad, A. Cornelius, and J. Isaza-Castro. 2012. "Effectiveness of Agricultural Interventions That Aim to Improve Nutritional Status of Children: Systematic Review." BMJ 344: d8222.

Masters, W. A., Y. Bai, A. Herforth, D. Sarpong, F. Mishili, J. Kinabo, and J. Coatesl. 2018. "Measuring the Affordability of Nutritious Diets in Africa: Price Indexes for Diet Diversity and the Cost of Nutrient Adequacy." American Journal of Agricultural Economics 100: $1285-1301$.

Masters, W. A., M. Nene, and W. Bell. 2017. "Nutrient Composition of Premixed and Packaged Complementary Foods for Sale in Low- and Middle-Income Countries: Lack of Standards Threatens Infant Growth." Maternal \& Child Nutrition 13: e12421-n/a.

Melo, P. C., Y. Abdul-Salam, D. Roberts et al. 2015. Income Elasticities of Food Demand in Africa: A Meta-Analysis. Publications Office of the European Union.

Micha, R., S. Khatibzadeh, P. Shi, K. Andrews, R. Engell, D. Mozaffarian, and Nutrition and Chronic Diseases Expert Group. 2015. "Global, Regional and National Consumption of Major Food Groups in 1990 and 2010: A Systematic Analysis Including 266 CountrySpecific Nutrition Surveys Worldwide." BMJ Open 5: e008705.

Mulmi, P., S. Block, G. Shively, and W. Masters. 2016. "Climatic Conditions and Child Height: Sex-Specific Vulnerability and the Protective Effects of Sanitation and Food Markets in Nepal." Economics \& Human Biology 23: 63-75.

Ngure, F. M., J. Humphrey, M. Mbuya et al. 2013. "Formative Research on Hygiene Behaviors and Geophagy among Infants and Young Children and Implications of Exposure to Fecal Bacteria." American Journal of Tropical Hygiene \& Medicine 89: 709-716. 
Pauw, K., and J. Thurlow. 2010. Agricultural Growth, Poverty, and Nutrition in Tanzania, 2010 AAAE Third Conference/AEASA 48th Conference. Cape Town: African Association of Agricultural Economists (AAAE); Agricultural Economics Association of South Africa (AEASA).

Pingali, P. L., and K. D. Ricketts. 2014. "Mainstreaming Nutrition Metrics in Household Surveys-Toward a Multidisciplinary Convergence of Data Systems.” Annals of the New York Academy of Sciences 1331: 249-257.

Pinstrup-Andersen, P. 2013. "Nutrition-Sensitive Food Systems: From Rhetoric to Action." Lancet 382: 375-376.

Rosenzweig, M., and C. Udry. 2016. External Validity in a Stochastic World. Working Paper 22449. Cambridge, MA: National Bureau of Economic Research.

Ruel, M. T., and H. Alderman. 2013. "Nutrition-Sensitive Interventions and Programmes: How Can They Help to Accelerate Progress in Improving Maternal and Child Nutrition?" Lancet 382: 536-551.

Ruel, M. T., J. Harris, and K. Cunningham. 2013. “Diet Quality in Developing Countries.” In Diet Quality: An Evidence-Based Approach, Vol. 2, edited by V. R. Preedy. New York: Springer.

Ruel, M. T., A. Quisumbing, and M. Balagamwala. 2018. "Nutrition-Sensitive Agriculture: What Have We Learned So Far?” Global Food Security 17 (June): 128-153.

Sheahan, M., C. B. Barrett, and C. Goldvale. 2017. "Human Health and Pesticide Use in Sub-Saharan Africa.” Agricultural Economics. 48 (S1): 27-41.

Shively, G. E. 2017. “Infrastructure Mitigates the Sensitivity of Child Growth to Local Agriculture and Rainfall in Nepal and Uganda." Proceedings of the National Academy of Sciences 114: 903-908.

Sibhatu, K. T., and M. Qaim. 2017. "Rural Food Security, Subsistence Agriculture, and Seasonality.” PLOS ONE 12: e0186406.

- 2018. "Review: Meta-Analysis of the Association between Production Diversity, Diets, and Nutrition in Smallholder Farm Households." Food Policy 77: 1-18.

Singh, I., L. Squire, and J. Strauss. 1986. Agricultural Household Models: Extension, Application and Policy. Baltimore: Johns Hopkins University Press.

Smith, L. C., M. T. Ruel, and A. Ndiaye. 2004. Why Is Child Malnutrition Lower in Urban Than Rural Areas? IFPRI Discussion Paper 176. Washington, DC: IFPRI.

Springmann, M., D. Mason-D’Croz, S. Robinson et al. 2016. “Global and Regional Health Effects of Future Food Production under Climate Change: A Modelling Study.” Lancet 387: 1937-1946. 
Stevano, S., S. Kadiyala, D. Johnston, H. Malapit, E. Hull, and S. Kalamatianou. 2019.

"Time-Use Analytics: An Improved Way of Understanding Gendered Agriculture-

Nutrition Pathways." Feminist Economics 25: 1-22.

Subramanian, S., and A. Deaton 1996. "The Demand for Food and Calories." Journal of Political Economy 104: 133-162.

Thapa, G., and G. Shively. 2018. "A Dose-Response Model of Road Development and Child Nutrition in Nepal." Research in Transportation Economics 70: 112-124.

Thorne-Lyman, A., D. Spiegelman, and W. Fawzi. 2014. "Is the Strength of Association between Indicators of Dietary Quality and the Nutritional Status of Children Being Underestimated?" Maternal \& Child Nutrition 10: 159-160.

Tiberti, L., and M. Tiberti. 2018. "Food Price Changes and Household Welfare: What Do We Learn from Two Different Approaches?” Journal of Development Studies 54: 72-92.

Van Campenhout, B. 2007. "Modelling Trends in Food Market Integration: Method and an Application to Tanzanian Maize Markets." Food Policy 32: 112-127.

Verger, E. O., T. Ballard, M. C. Dop, and Y. Martin-Prevel. 2019. "Systematic Review of Use and Interpretation of Dietary Diversity Indicators in Nutrition-Sensitive Agriculture Literature.” Global Food Security 20: 156-169.

Victora, C. G., M. de Onis, P. C. Hallal, M. Blossner, and R. Shrimpton. 2010. “Worldwide Timing of Growth Faltering: Revisiting Implications for Interventions." Pediatrics 125 (3): e $473-480$.

von Braun, J. 1995. "Agricultural Commercialization: Impacts on Income and Nutrition and Implications for Policy." Food Policy 20: 187-202.

WHO (World Health Organization). 2006. "WHO Child Growth Standards Based on Length/ Height, Weight and Age." Acta Paediatrica Supplement 450: 76-85.

Wiggins, S., and S. Keats. 2015. The Rising Cost of a Healthy Diet: Changing Relative Prices of Foods in High-Income and Emerging Economies. Research Reports and Studies. London: Overseas Development Institute (ODI).

Zambrano, L. D., K. Levy, N. Menezes, and M. Freeman. 2014. “Human Diarrhea Infections Associated with Domestic Animal Husbandry: A Systematic Review and Meta-Analysis." Transactions of the Royal Society of Tropical Medicine \& Hygiene 108: 313-325.

Zanello, G., C. S. Srinivasen, and B. Shankar. 2016. "What Explains Cambodia's Success in Reducing Child Stunting-2000-2014?” PLOS ONE 11: e0162668. 